\title{
円板の境界条件の実験的同定法* （線形の軸対称問題の場合）
}

\author{
安田仁 彦*1, 崔 勇 俊*2 \\ Experimental Identification Technique for Boundary Conditions \\ of a Circular Plate \\ (Linear Axisymmentrical Problems)
}

Kimihiko YASUDA and Cui Yong JUN

\begin{abstract}
As a basis for developing experimental identification techniques for boundary conditions of a plate, a technique applicable to a circular plate in linear axisymmetrical ploblems is proposed. The proposed technique enables one to determine, using data of dynamic responses of a plate, the boundary conditions in terms of spring constants, damping coefficients, and equivalent masses and moments of inertia. Numerical simulation is conducted, and the applicability of the proposed technique is confirmed.
\end{abstract}

Key Words: Vibration, Boundary Conditions, Circular Plate, Axisymmetrical Problem, Linear System, Dynamic Response

\section{1. まえ がき}

機械・機器・構造物の高速化, 高性能化, 軽量化に対 する要求とともに, これらの対象物の動的問題に対す る数学モデルを精度よく作成することがますます重要 となってきている.このため, 理論的モデル化の結果 と対象物の動的応答の実験データを融合して,よりょ い数学モデルを作成しようとする実験的同定が大きな 関心を呼んでいる.

実験的同定の問題のうち, 境界条件の同定について は, 必要性は指摘されながら(1)(2), これを扱った研究 は少ない.前報で著者の一人は, はりを対象にして, 本 体の動的応答の赛験データを用いて境界条件を同定す る方法に関する基礎的検討を行った (3).

この研究は, 板のような二次元的構造物の境界条件 の同定の問題の基礎的検討を目的にする.このため簡 単な場合として円板を取上げ，軸対称問題に対して， 境界条件を実験的に同定する方法を提案する．前報の はりの場合と同じように，境界部に外力を加えたり境

* 原稿受付 1995 年 2 月 28 日.

*1 正員, 名古屋大学工学研究科 (《464-01 名古屋市千種区不老 町).

*2 准冒, 名古屋大学大学院.
界部の応答を測定できない場合を想定する．数值シミ ユレーションにより，提案した同定法の有効性を検討 する.

\section{2. 実験的同定法の提案}

\section{$2 \cdot 1$ 問題設定 機械・機器・構造物の構成要素と} してしばしば円板が用いられる。いま円板単独での特 性は既知であるが, 組立状態での円板の境界条件が未 知のため，これを実験的に同定したいとする。

実験的同定のため, 図 1 に示すように, 境界部はた わみと傾きに対するばねとダンパでモデル化されるも のとする.ばねは線形であるとし，たわみに対するば ね定数を $k_{w}$ ，傾きに対するばね定数を $k_{\theta}$ とおく．ま たダンパは粘性隇衰を与えるものとし，たわみに対す る減衰係数を $c_{w}$, 傾きに対する減衰係数を $c_{\theta}$ とお く. 他の隇衰, 例えば構造隇衰が作用する場合にも以 下と同じように扱うことができる，問題によっては境

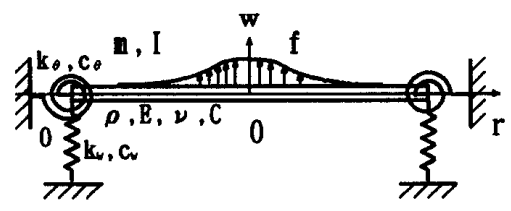

Fig. 1 Circular plate 
界部に等価な質量と慣性モーメントを考える必要があ るので，これらを $m$ および $I$ とする。このとき境界条 件の実験的同定とは，円板の動的応答の実験デー夕を 用いて，ばね定数 $k_{w}, k_{\theta}$ ，隇衰係数 $c_{w}, c_{\theta}$ および等価 な質量と慣性モーメント $m, I$ の未知パラメータを定 めることである。

実験的同定の前提として，境界部に外力を加えたり 境界部の動的応答を測定することが困難な場合を想定 し，円板の本体に外力を加えて得られる本体の動的応 答の実験デー夕のみが利用できるとする。

$2 \cdot 2$ 運動方程式と光の解 実験的同定法の提案 のため，円板の運動方程式とその解を考える．円板は 密度 $\rho$, 絽弾性係数 $E$, ポアソン比 $\nu$ の材料からなり, 半径 $a$, 厚さ $h$ とする. 静止時の円板の中心を原点 $\mathrm{O}$ とし, 極座標 $(r, \theta)$ を定める. 横方向の外力 $f$ によっ てたわみ $w$ を生じるものとする，軸対称問題では $f$, $w$ はいずれも座標 $r$ と時間 $t$ の関数である. 円板の本 体に粘性減衰が作用する場合を考え，減衰係数を $C$ とおくこことき運動方程式は

$$
D \nabla^{4} w+C \frac{\partial w}{\partial t}+\rho h \frac{\partial^{2} w}{\partial t^{2}}=f
$$

となる.ここに

$$
\nabla^{2}=\frac{\partial^{2}}{\partial r^{2}}+\frac{1}{r} \frac{\partial}{\partial r}
$$

であり,また

$$
D=\frac{E h^{3}}{12\left(1-\nu^{2}\right)}
$$

である。

境界条件は, $r=a$ において

$$
\begin{aligned}
& D \frac{\partial}{\partial r}\left(\nabla^{2} w\right)=k_{w} w+c_{w} \frac{\partial w}{\partial t}+m \frac{\partial^{2} w}{\partial t^{2}}, \\
& D\left(\frac{\partial^{2} w}{\partial r^{2}}+\frac{\nu}{r} \frac{\partial w}{\partial r}\right)=-k_{\theta} \frac{\partial w}{\partial r}-c_{\theta} \frac{\partial^{2} w}{\partial t \partial r}-I \frac{\partial^{3} w}{\partial t^{2} \partial r}
\end{aligned}
$$

が満たされることである.

外力として, 角振動数 $\omega$ の調和外力

$$
f=F(r) \cos \omega t
$$

を作用させるものとする。ここに $F(r)$ は調和外力の 大きさを表し, 座標 $r$ の関数である.このとき応答 $w$ は

$$
w=W(r) \cos \omega t+W^{*}(r) \sin \omega t
$$

の形をとる.ここに $W(r), W^{*}(r)$ は座標 $r$ の未知関 数で, $r$ の位置における振幅の $\cos$ 成分, $\sin$ 成分の 振幅を表す. 式(6)を式 (1)に代入し，

$$
\alpha^{4}=\frac{\rho h \omega^{2}}{D}, \beta^{4}=\frac{C \omega}{D}
$$

を導入すると, $W(r), W^{*}(r)$ を定める式として

$$
\nabla^{4} W(r)+\beta^{4} W^{*}(r)-\alpha^{4} W(r)=\frac{F(r)}{D},
$$

$$
\nabla^{4} W^{*}(r)-\beta^{4} W(r)-\alpha^{4} W^{*}(r)=0
$$

を得る.この式の一般解を求めよう。

まず式 ( 8 ) の右辺を零とおいて得られる同次方程式 の一般解を求める。このため零次の円柱関数 $Z_{0}$ を用 いて, 求める解を

$$
W(r)=A Z_{0}(\lambda r), W^{*}(r)=A^{*} Z_{0}(\lambda r)
$$

の形におく.ここに $A, A^{*}, \lambda$ は定数である。これが解 となるための条件は

$$
\left.\begin{array}{l}
\left(\lambda^{4}-\alpha^{4}\right) A+\beta^{4} A^{*}=0 \\
-\beta^{4} A+\left(\lambda^{4}-\alpha^{4}\right) A^{*}=0
\end{array}\right\}
$$

である。したがって

$$
\left(\lambda^{4}-\alpha^{4}\right)^{2}+\beta^{8}=0
$$

が満たされるとき, 式 ( 9 ) は求める解となる。 この式 の根 $\lambda$ は

$$
\begin{aligned}
& \lambda= \pm\left(a_{0}+j b_{0}\right), \pm\left(b_{0}-j a_{0}\right), \pm\left(a_{0}-j b_{0}\right), \\
& \pm\left(b_{0}+j a_{0}\right)
\end{aligned}
$$

の形におくことができる．ここで $a_{0}, b_{0}$ は式(11)から 容易に求められる.これらの根は,

$$
\left.\begin{array}{l}
\rho_{0} \cos \phi_{1}=a_{0}, \rho_{0} \sin \phi_{1}=b_{0} \\
\rho_{0} \cos \phi_{2}=b_{0}, \rho_{0} \sin \phi_{2}=a_{0}
\end{array}\right\}
$$

で定められる $\rho_{0}, \phi_{1}, \phi_{2}$ を用いて

$$
\begin{aligned}
\lambda= & \pm \rho_{0} e^{+j \phi_{1}}, \pm \rho_{0} e^{-j \phi_{2}}, \\
& \pm \rho_{0} e^{-j \phi_{1}}, \pm \rho_{0} e^{+j \phi_{2}}
\end{aligned}
$$

の形に扔くこともできる．以下ここではこの形の根を 用いる。これらの各根に対し， $A, A^{*}$ の比

$$
\varkappa=\frac{A^{*}}{A}=-\frac{\lambda^{4}-\alpha^{4}}{\beta^{4}}
$$

を求めると, 前の 2 組, 後の 2 組の根に対しそれぞれ

$$
\boldsymbol{\kappa}=-j,+j
$$

を得る.以上から， $r \rightarrow 0$ で特異とならない一般解とし $\tau$

$$
\left.\begin{array}{c}
W(r)=A_{1} J_{0}\left(\rho_{0} e^{j \phi_{1}} r\right)+A_{2} J_{0}\left(\rho_{0} e^{-j \phi_{2}} r\right) \\
+A_{3} J_{0}\left(\rho_{0} e^{-j \phi_{1}} r\right)+A_{4} J_{0}\left(\rho_{0} e^{j \phi_{2}} r\right) \\
W^{*}(r)=-A_{1} j J_{0}\left(\rho_{0} e^{j \phi_{1}} r\right)-A_{2} j J_{0}\left(\rho_{0} e^{-j \phi_{2}} r\right) \\
+A_{3} j J_{0}\left(\rho_{0} e^{-j \phi_{1}} r\right)+A_{4} j J_{0}\left(\rho_{0} e^{j \phi_{2}} r\right)
\end{array}\right\}
$$

を得る.ここに $A_{i}(i=1,2,3,4)$ は任意定数である.こ の式で $J_{0}\left(\rho_{0} e^{j \phi_{1}} \gamma\right), J_{0}\left(\rho_{0} e^{j \phi_{2}} \gamma\right)$ などを実部と虚部に分 け,

$$
\left.\begin{array}{l}
J_{0}\left(\rho_{0} e^{ \pm j \phi_{1}} r\right)=u_{01}(r) \pm j v_{01}(r) \\
J_{0}\left(\rho_{0} e^{ \pm j \phi_{2}} r\right)=u_{02}(r) \pm j v_{02}(r)
\end{array}\right\}
$$

とおけば, 式(17)は

$$
\left.\begin{array}{c}
W(r)=C_{1} u_{01}(r)+C_{2} v_{01}(r) \\
+C_{3} u_{02}(r)+C_{4} v_{02}(r) \\
W^{*}(r)=-C_{2} u_{01}(r)+C_{1} v_{01}(r) \\
+C_{4} u_{02}(r)-C_{3} v_{02}(r)
\end{array}\right\}
$$


となる.ここに $C_{i}(i=1,2,3,4)$ は任意定数である. 次に式( 8$)$ の特解を求める. $W(r), W^{*}(r), F(r)$ の ハンケル変換を $\bar{W}(\xi), \overline{W^{*}}(\xi), \bar{F}(\xi)$ で表すと, 式 (8)から

$$
\left.\begin{array}{l}
\left(\xi^{4}-\alpha^{4}\right) \bar{W}(\xi)+\beta^{4} \overline{W^{*}}(\xi)=\frac{\bar{F}(\xi)}{D} \\
-\beta^{4} \bar{W}(\xi)+\left(\xi^{4}-\alpha^{4}\right) \overline{W^{*}}(\xi)=0
\end{array}\right\}
$$

を得る。したがって

$$
\left.\begin{array}{l}
\bar{W}(\xi)=\frac{\bar{F}(\xi)}{D} \frac{\xi^{4}-\alpha^{4}}{\left(\xi^{4}-\alpha^{4}\right)^{2}+\beta^{8}} \\
W^{*}(\xi)=\frac{\bar{F}(\xi)}{D} \frac{\beta^{4}}{\left(\xi^{4}-\alpha^{4}\right)^{2}+\beta^{8}}
\end{array}\right\}
$$

が得られ, 特解として

$$
\left.\begin{array}{l}
W(r)=\frac{1}{D} \int_{0}^{\infty} \bar{F}(\xi) \frac{\xi^{4}-\alpha^{4}}{\left(\xi^{4}-\alpha^{4}\right)^{2}+\beta^{8}} \xi J_{0}(\xi r) d \xi \\
W^{*}(r)=\frac{1}{D} \int_{0}^{\infty} \bar{F}(\xi) \frac{\beta^{4}}{\left(\xi^{4}-\alpha^{4}\right)^{2}+\beta^{8}} \xi J_{0}(\xi r) d \xi
\end{array}\right\}
$$

を得る. $\bar{F}(\xi)$ は, 外力 $F(r)$ を与えればハンケル変換 の定義式

$$
\bar{F}(\xi)=\int_{0}^{\infty} r F(r) J_{0}(\xi r) d r
$$

によって求められる。例えば半径 $r_{f}$ 上で一定の值を とり, 大きさが $F_{0}$ である調和外力に対しては

$$
\bar{F}(\xi)=\frac{F_{0}}{2 \pi} J_{0}\left(r_{f} \xi\right)
$$

となる.この式で特に $r_{f} \rightarrow 0$ とすれば

$$
\bar{F}(\xi)=\frac{F_{0}}{2 \pi}
$$

となる。これを用いれば, 円板中心に集中外力が作用 するときの特解は

$$
\left.\begin{array}{l}
W(r)=\frac{F_{0}}{2 \pi D} \int_{0}^{\infty} \frac{\xi^{4}-\alpha^{4}}{\left(\xi^{4}-\alpha^{4}\right)^{2}+\beta^{8}} \xi J_{0}(\xi r) d \xi \\
W^{*}(r)=\frac{F_{0}}{2 \pi D} \int_{0}^{\infty} \frac{\beta^{4}}{\left(\xi^{4}-\alpha^{4}\right)^{2}+\beta^{8}} \xi J_{0}(\xi r) d \xi
\end{array}\right\}
$$

となる. 以下このような特解を $G(r), G^{*}(r)$ とおく. 以上から, 式(8)の一般解は

$$
\left.\begin{array}{l}
W(r)=C_{1} u_{01}(r)+C_{2} v_{01}(r)+C_{3} u_{02}(r) \\
\quad+C_{4} v_{02}(r)+G(r) \\
W^{*}(r)=-C_{2} u_{01}(r)+C_{1} v_{01}(r)+C_{4} u_{02}(r) \\
\quad-C_{3} v_{02}(r)+G^{*}(r)
\end{array}\right\}
$$

となる. 定数 $C_{i}(i=1,2,3,4)$ は境界条件によって定 められる。

$2 \cdot 3$ 実験的同定法 以上によって準備が整った ので, 円板の動的応答の実験データから, 円板の境界 条件を同定する方法を考える. 前述のように円板の特 性はあらかじめ測定されているとする。
実験的同定のため, 式 ( 5 )の形の調和外力を円板に 作用させる. 角振動数 $\omega$ と大きさ $F(r)$ は適当に定め る. 円板の $N$ 個の点 $r=r_{i}(i=1,2, \cdots, N)$ において, この外力に対する定常状態の動的応答のたわみの $\cos$ 成分, $\sin$ 成分の振幅を測定し，その值を $W\left(r_{i}\right)$, $W^{*}\left(r_{i}\right)$ と扔く.これは式(27) を満たしているから

$$
\left.\begin{array}{l}
u_{01}\left(r_{i}\right) C_{1}+v_{01}\left(r_{i}\right) C_{2}+u_{02}\left(r_{i}\right) C_{3}+v_{02}\left(r_{i}\right) C_{4} \\
=W\left(r_{i}\right)-G\left(r_{i}\right) \\
-u_{01}\left(r_{i}\right) C_{2}+v_{01}\left(r_{i}\right) C_{1}+u_{02}\left(r_{i}\right) C_{4}-v_{02}\left(r_{i}\right) C_{3} \\
=W^{*}\left(r_{i}\right)-G^{*}\left(r_{i}\right)
\end{array}\right\}
$$

が成り立つ、これは $C_{i}(i=1,2,3,4)$ に関する線形方 程式である. したがって测定点の数 $N$ を 2 として, $r$ $=r_{1}, r_{2}$ に対して式(28)の方程式を連立させて解けば, $C_{i}$ を定めることができる.実際には測定データにノイ ズが含まれることを考慮して $N$ を 2 より大きくした 場合のデー夕を用いて，式(28)の形の方程式に最小二 乗法を適用して $C_{1}, C_{2}, C_{3}, C_{4}$ を定める。それらを式 (27) に代入して $W(r), W^{*}(r)$ を定める。この結果を 式(6)に代入して $w$ を定め，それを式 (4)に代入し て両辺の $\cos$ 成分, $\sin$ 成分の係数を等しいとおいて, 境界条件の未知パラメータに関する方程式を得る。円 板に作用させる調和外力の大きさ $F(r)$ を変えて同じ ようにして方程式を求め, 未知パラメータに関する十 分な数の方程式を求める。このようにして得られる連 立方程式に再び最小二乗法を適用して未知パラメータ を定める.もし末知パラメータが角振動数 $\omega$ に依存し ないと考えられる場合には， $\omega$ を変えて得られる方程 式も含め最小二乗法を適用する，以上が提案する同定 法である。

\section{3. 数值シミュレーション}

2 章で提案した実験的同定法の有効性を，数値シミ ュレーションによって確かめることにする.このため, 数值的に得た動的応答のデータを実験データとみな し，このデータを用いて提案した同定法によって未知 パラメータを定め, パラメータのもとの值と比較する 方法をとる。

数值計算のため, 円板の諸元を

半径 $a=200 \mathrm{~mm}$

厚さ $h=0.3 \mathrm{~mm}$

繸弾性係数 $E=2.06 \times 10^{11} \mathrm{~Pa}$

密度 $\rho=7.84 \times 10^{3} \mathrm{~kg} / \mathrm{m}^{3}$

減衰係数 $C=1 \mathrm{Ns} / \mathrm{m}^{2}$ とする。 
3・1 境界部の等価签量，等価慣性モーメントを考 虑する必要がない場合＼cjkstart境界部が軽いものからでき ている場合のように，境界部の等価質量や等価慣性モ ーメントを考慮する必要がない場合をはじめに考え る.

数值シミュレーションのため, 境界におけるパラメ ータの值を

$$
\left.\begin{array}{l}
k_{w}=1 \times 10^{4} \mathrm{~N} / \mathrm{m}, k_{\theta}=6 \times 10^{2} \mathrm{Nm} / \mathrm{rad} \\
c_{w}=5 \mathrm{Ns} / \mathrm{m}, c_{\theta}=3 \mathrm{Nms} / \mathrm{rad}
\end{array}\right\}
$$

と定める。 また外力は円板中心に作用する集中調和外 カとし，その大きさ $F_{0}$ を

$$
F_{0}=0.1 \mathrm{~N}
$$

とする.

動的応答の数值例として, 外力の振動数 $\omega$ を $\omega=$
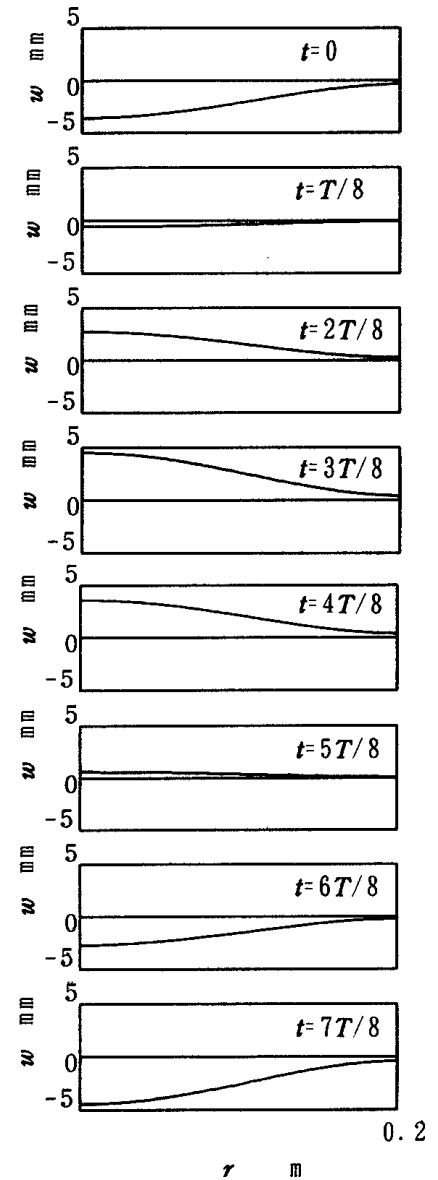

Fig. 2 Response of circular plate $(\omega=105 \mathrm{rad} / \mathrm{s})$

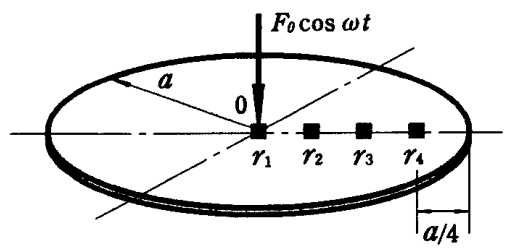

Fig. 3 Points of measurement
$105 \mathrm{rad} / \mathrm{s}$ とした場合に得られた結果を示すと図 2 の ようになった。図 2 は，周期 $T$ を 8 等分した各時刻に

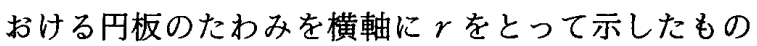
である。このような動的応答を実験デー夕とみなす。

応答の測定点を, 図 3 に示すように, 円板の中心お よび半径を 4 等分する三つの分割点をあわせた四つの 点 $r_{i}(i=1,2,3, \dot{4})$ とする.

同定に用いる外力の角振動数 $\omega$ を定めるため, $\omega$ を $0 \mathrm{rad} / \mathrm{s}$ から $400 \mathrm{rad} / \mathrm{s}$ の範囲で変化させて応答を求 めた。例として点 $r_{3}$ に扔けるたわみの振幅 $(W)_{3}$ を $\omega$

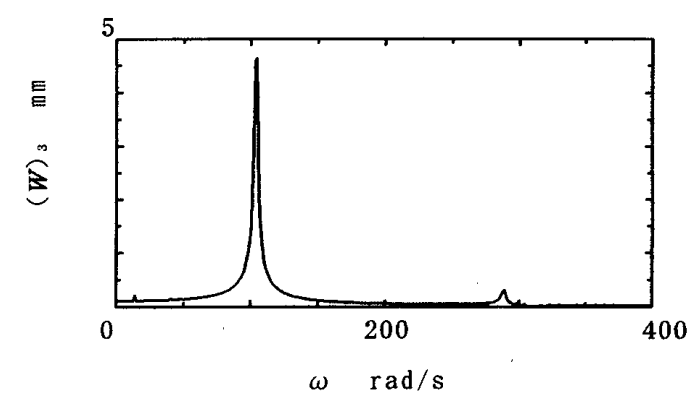

Fig. 4 Amplitude at point $r_{3}$
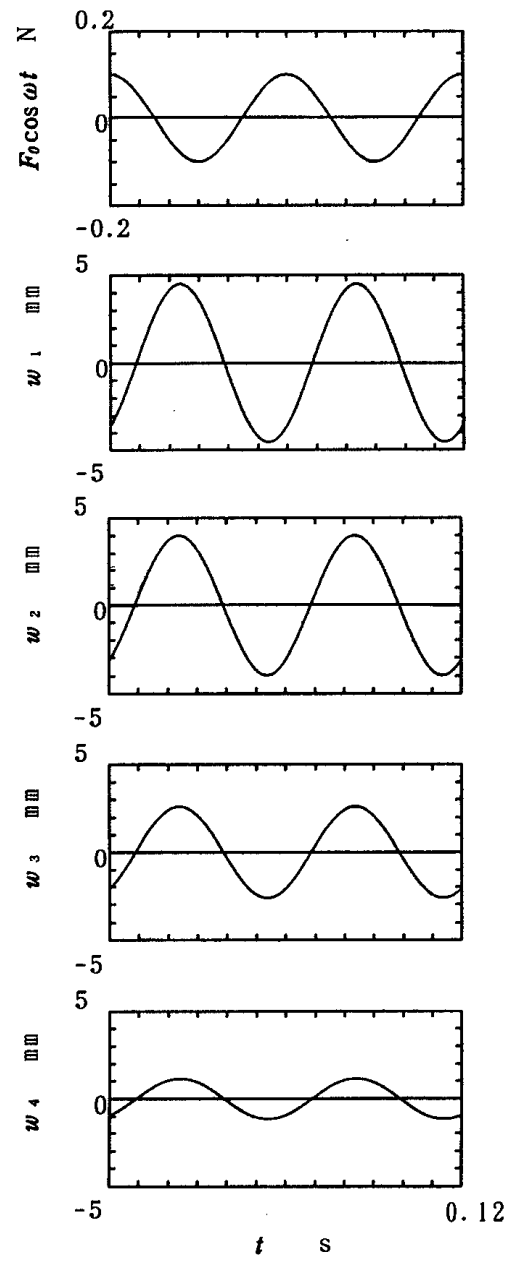

Fig. 5 Deflection at points of measurement 
Table 1 Value of $C_{i}(i=1,2,3,4)$

\begin{tabular}{|l|l|}
\hline$C_{1}$ & $-3.2852 \times 10^{-3}$ \\
\hline$C_{2}$ & $-2.5302 \times 10^{-3}$ \\
\hline$C_{3}$ & $-2.4656 \times 10^{-4}$ \\
\hline$C_{4}$ & $1.8815 \times 10^{-4}$ \\
\hline
\end{tabular}

Table 2 Results of identification

\begin{tabular}{|l|l|l|}
\hline Parameters & Original & Identified \\
\hline $\mathrm{k}_{w}(\mathrm{~N} / \mathrm{m})$ & $1.0 \times 10^{4}$ & $1.0000 \times 10^{4}$ \\
$\mathrm{k}_{\theta}(\mathrm{Nm} / \mathrm{rad})$ & $6.0 \times 10^{2}$ & $6.0000 \times 10^{2}$ \\
$\mathrm{C}_{w}(\mathrm{Ns} / \mathrm{m})$ & 5.0 & 5.0000 \\
$\mathrm{C}_{\theta}(\mathrm{Nms} / \mathrm{rad})$ & 3.0 & 2.9999 \\
$\mathrm{~m}(\mathrm{~kg})$ & 0.0 & $3.50 \times 10^{-15}$ \\
$\mathrm{I}\left(\mathrm{kgm}^{2}\right)$ & 0.0 & $-2.75 \times 10^{-14}$ \\
\hline
\end{tabular}

Table 3 Value of $C_{i}(i=1,2,3,4)$

\begin{tabular}{|l|l|}
\hline$C_{1}$ & $9.3682 \times 10^{-5}$ \\
\hline$C_{2}$ & $-2.0641 \times 10^{-5}$ \\
\hline$C_{3}$ & $-6.9503 \times 10^{-6}$ \\
\hline$C_{4}$ & $3.6718 \times 10^{-6}$ \\
\hline
\end{tabular}

Table 4 Results of identification

\begin{tabular}{|l|l|l|}
\hline Parameters & Original & Identified \\
\hline $\mathrm{k}_{w}(\mathrm{~N} / \mathrm{m})$ & $1.0 \times 10^{4}$ & $9.9999 \times 10^{3}$ \\
$\mathrm{k}_{\theta}(\mathrm{Nm} / \mathrm{rad})$ & $6.0 \times 10^{2}$ & $6.0000 \times 10^{2}$ \\
$\mathrm{c}_{w}(\mathrm{Ns} / \mathrm{m})$ & 5.0 & 5.0000 \\
$\mathrm{c}_{\theta}(\mathrm{Nms} / \mathrm{rad})$ & 3.0 & 3.0000 \\
$\mathrm{~m}(\mathrm{~kg})$ & $1.0 \times 10^{1}$ & 9.9999 \\
$\mathrm{I}\left(\mathrm{kgm}^{2}\right)$ & $1.0 \times 10^{2}$ & $1.0000 \times 10^{2}$ \\
\hline
\end{tabular}

の関数として示すと図 4 のようになった。この図から， 円板の共振点は $103 \mathrm{rad} / \mathrm{s}$ と $288 \mathrm{rad} / \mathrm{s}$ の付近にある ことがわかる，そこでここでは，1 次の共振点付近の $105 \mathrm{rad} / \mathrm{s}$ を同定に用いる外力の角振動数とする.

この角振動数に対して, 各測定点におけるたわみの 時間変化を求めたところ図 5 のようになった. 図の $w_{i}$ $(i=1,2,3,4)$ は点 $r=r_{i}$ におけるたわみを表す。この データから, 振動の $\cos$ 成分と $\sin$ 成分を求めたとこ ろ図6のようになった。この図で $W_{i}, W_{i}^{*}$ は $W\left(r_{i}\right)$, $W^{*}\left(r_{i}\right)$ を表し，また右肩の正負の符号は各成分の值 の正負を示す.この結果を式(28)に代入し, $C_{i}(i=1$, $2,3,4)$ を求めたところ, 表 1 のような結果が得られ た。これを式(27)に代入し，その結果を式(6)に代入 し，さらにそれを式（4）に代入して未知パラメータを
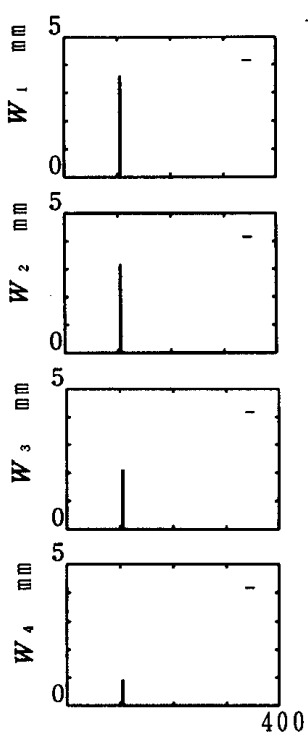

$\omega \mathrm{rad} / \mathrm{s}$
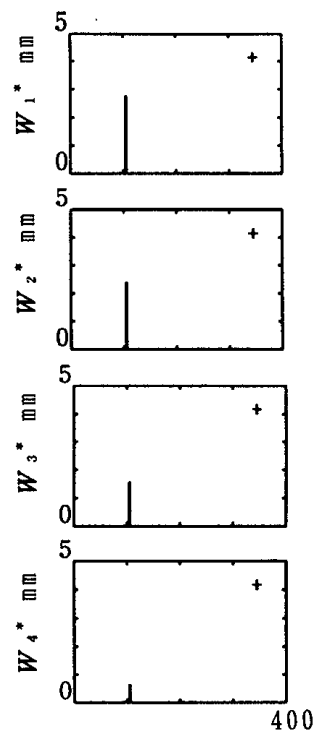

$\omega \mathrm{rad} / \mathrm{s}$

Fig. 6 cos and sin components of deflection

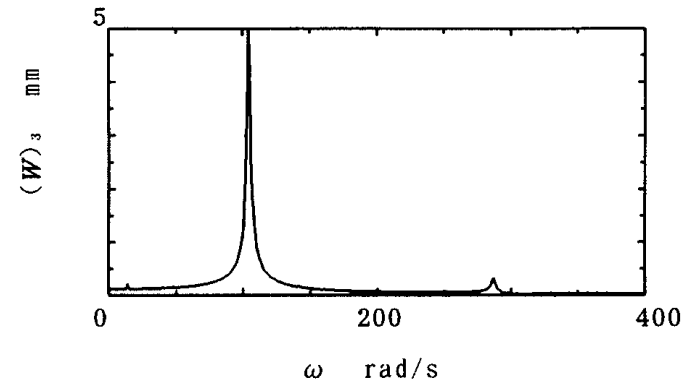

Fig. 7 Amplitude at point $r_{3}$

定めたところ，表 2 のような結果が得られた．表から， 同定によるパラメータの值は式(30)で与えられるもと の值と一致し，したがって提案した同定法が有効であ ることがわかった。

$3 \cdot 2$ 境界部の等価質量, 等価慣性モーメントを考

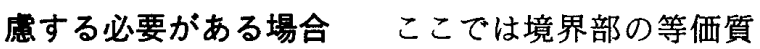
量, 等価慣性モーメントを考慮する必要がある, 一般 の場合を取上げる。

数值シミュレーションのため円板の諸元, 外力, 応 答の測定位置などは $3 \cdot 1$ 節と同じとする，境界におけ るパラメータのうち $k_{w}, k_{\theta}, c_{k}, c_{\theta}$ は $3 \cdot 1$ 節と同じ值 とし, 等価質量 $m$, 等価慣性モーメント $I$ を

$m=10 \mathrm{~kg}, I=100 \mathrm{~kg} \cdot \mathrm{m}^{2}$ と定める。

以上の場合に, 例えば $r=r_{3}$ の位置における円板の たわみの振幅 $(W)_{3}$ は図 7 のようになった。同定に用 いる外力の角振動数は前と同じ $\omega=105 \mathrm{rad} / \mathrm{s}$ とした。 前と同じ取扱いによって定数 $C_{i}(i=1,2,3,4)$ を定め たところ, 表 3 に示す結果を得た。これを用いて境界 
部の未知パラメー夕を求めたところ, 表 4 のような結 果を得た。表から, 同定によるパラメータはもとの值 によく一致し，したがってこの場合にも提案した同定 法が有効であることがわかった。

\section{4. むす び}

境界条件の実験的同定法の基礎的な検討を目的とし て円板を取上げ, 軸対称問題に対して，境界条件を同 定する新しい方法を提案した。提案した同定法は，境 界部をばね，ダンパおよび等価な質量と慣性モーメン
トで置き換え，それらの大きさを，円板の本体の調和 外力に対する動的応答のデー夕を用いて定めるもので ある. 数値シミュレーションによって，提案した同定 法が有効であることを確認した。

\section{文献}

（1）田中・三枝, 振動モデルとシミュレーション, (1984), 281, 応用技術出版。

（2）長松・大熊, 部分構造合成法, (1991), 26, 培風館.

（3）安田・後藤，はりの境界条件の実験的同定法(境界条件が 線形の場合), 機論, 60-570, C(1994), 482-489. 